\title{
INOVAÇÃO EM POLÍTICAS DE TREINAMENTO E DESENVOLVIMENTO: UM ESTUDO COMPARATIVO EM TRÊS ORGANIZAÇÕES
}

\author{
D. R. NETO, F. L. MESQUITA, K. A. MARQUES, A. C. SILVA e M. R. BARROS \\ Universidade Federal de Goiás \\ denisianeto@hpeautos.com.br*
}

Submetido 18/07/2016 - Aceito 20/08/2017

DOI: $10.15628 /$ holos.2017.4849

\section{RESUMO}

Este trabalho teve como objetivo compreender as políticas e práticas de treinamento e desenvolvimento de empresas de grande porte que possuem uma área de recursos humanos estruturada e como estas empresas inovam suas políticas e práticas de desenvolvimento para valorização dos colaboradores. Para o alcance desse objetivo, foi realizada uma revisão bibliográfica e uma pesquisa documental, utilizando relatórios emitidos pelas organizações, e ainda uma entrevista com perguntas abordando o processo de desenvolvimento organizacional. Para análise dos dados e resultados, utilizou-se da matriz SWOT, focalizando as três empresas selecionadas. Como conclusão, verificou-se que cada uma destas empresas apresenta diferentes políticas e formas de desenvolver e manter seus empregados, levando em consideração as decisões estratégicas e os objetivos a serem alcançados.

PALAVRAS-CHAVE: Treinamento, Desenvolvimento, Inovação

\section{INNOVATION IN TRAINING AND DEVELOPMENT POLICIES: A COMPARATIVE STUDY IN THREE ORGANIZATIONS}

\begin{abstract}
This study aimed to understand the policies and practices of training and development of large companies that have a structured human resources area and how these companies innovate their policies and development practices for employee appreciation. In order to achieve that goal, a bibliographic review and a documentary research were carried out, using reports issued by the organizations, as well as an interview with
\end{abstract}

questions addressing the process of organizational development. For analyses of data and results, the SWOT matrix was used, focusing on the three selected companies. In conclusion, it was verified that each of these companies presents different policies and ways to develop and maintain their employees, taking into account the strategic decisions and objectives to be reached.

KEYWORDS: Training, Development, Innovation. 


\section{INTRODUÇÃO}

A economia nacional passa por um período de grande recessão. Essa crise afeta todos os segmentos da sociedade, empresas, órgãos sociais e entidades civis e filantrópicas, com fins e sem fins lucrativos. Com as quedas na produção industrial, cresce a expectativa de falência para as empresas brasileiras. A economia brasileira foi tomada pela inércia e estagnação gradual de diversos setores, sendo o automobilístico o mais afetado por essa crise.

Devido a esse período de recessão economia nacional, o setor automobilístico planejou para 2016 uma redução significativa em todos seus recursos, considerando dessa forma um cenário desafiador para a gestão de pessoas. O segmento teve uma queda de 22,8\% em 2015 com relação a 2014, segundo índices apresentados pela ANFAVEA (Associação Nacional dos Fabricantes de Veículos Automotores). Consequentemente, houve uma redução do índice do total de colaboradores em todas as fábricas automobilísticas no país. Além de uma redução no quadro de pessoal, as medidas de retenção de gastos se tornaram constantes a fim de se promover uma sustentabilidade em um momento que apresenta insegurança para o ano vigente e ainda para os próximos dois anos.

Com a redução do quadro de pessoal, os novos ativos das indústrias automobilísticas são as pessoas que a elas prestam serviços. Essas indústrias precisam conquistar, aplicar, reter, motivar, recompensar e desenvolver novos talentos. As competências individuais das pessoas, tais como habilidades, conhecimentos, capacidade para gerar novas estratégias, são responsabilidades inerentes ao gestor de recursos humanos. Ele precisa saber aproveitar o potencial de cada pessoa que presta serviços à organização.

Nesse contexto, se destacam as políticas de recursos humanos destinadas a motivar e capacitar os trabalhadores, visando melhorias na qualificação de mão-de-obra, incentivos para que a produção seja além da média traçada pelas indústrias automobilísticas. O grande desafio dessas indústrias é investir na área de gestão de pessoas, a fim de que o desenvolvimento e a capacitação da mão-de-obra não sejam apenas uma tarefa exclusiva da área de treinamento e desenvolvimento, mas sim de todos os executivos da organização.

Dessa forma, os processos de treinamento e desenvolvimento de pessoas dentro das organizações, principalmente no setor automobilístico, tornam-se vitais diante deste cenário. Para efeito deste estudo, o treinamento corresponde a um processo educacional, que pode ser de curto, médio ou longo prazo, sendo organizado de maneira sistemática e envolve transmissão de conhecimento por meio de atividades educativas. Nesse sentido, o treinamento torna-se uma das atividades desenvolvidas pela gestão de pessoas que visa a obtenção de melhorias na qualidade dos serviços prestados à organização. $O$ desenvolvimento de uma pesquisa direcionada ao setor automobilístico tem como justificativa criar estratégias de treinamento que possam contribuir para o desenvolvimento de seus colaboradores.

Assim, através da presente pesquisa foi possível identificar se as políticas de treinamento e desenvolvimento adotadas por três indústrias de segmentos diferenciados, situadas em Catalão-Goiás, são inovadoras e se contribuem para a capacitação e melhoria da qualidade dos serviços prestados por seus colaboradores. Essas indústrias foram previamente selecionadas, pois seus departamentos de Recursos Humanos encontram-se instalados nas respectivas 
organizações, situadas na cidade mencionada, o que facilitou a realização do estudo. Dentre os objetivos específicos destacam-se: descrever as ações de desenvolvimento para a gestão de pessoas; apontar as diferenças das políticas de treinamento e desenvolvimento nas indústrias. Para o alcance desses objetivos segue-se uma fundamentação teórica abordando a gestão de pessoas, as políticas de treinamento e desenvolvimento para as empresas. Também, segue-se um estudo de caso referente às três empresas pesquisadas para realização deste estudo, em sequência análise dos dados e resultados e, por fim, a conclusão.

\section{REVISÃO BIBLIOGRÁFICA}

A primeira etapa consiste na revisão bibliográfica a partir da leitura seletiva e exploratória, contemplando vários autores que discutem sobre tema norteado. A pesquisa bibliográfica sobre a temática apresentada efetuou-se no levantamento de informações sobre os assuntos desejados, em artigos científicos publicados na SCIELO, Google Acadêmico e ANPAD (Associação Nacional de Pós-Graduação e Pesquisa em Administração).

\subsection{Gestão de Pessoas}

Na visão de Chiavenato (2010), a Gestão de Pessoas (GP) refere-se ao conjunto de atividades envolvidas na administração de pessoal, as quais são desenvolvidas por especialistas e gestores. Assim sendo, os gestores passam a ser gestores de pessoas, que participam efetivamente das práticas de GP, tomando decisões acerca dos seus colaboradores. Ainda na perspectiva deste autor, a Gestão de Pessoas abrange seis processos, a saber: Processos de agregar pessoas, processos de aplicar pessoas, processos de recompensar pessoas, processos de desenvolver pessoas, processos de manter pessoas e processos de monitorar pessoas.

Dentre esses processos destacam-se os processos de desenvolver pessoas, que são o alvo deste estudo. Incluem-se nesses processos o treinamento, o desenvolvimento de pessoas, a aprendizagem e a gestão do conhecimento. No intuito de gerenciar os comportamentos internos e desenvolver o capital humano nas organizações, a gestão de pessoas busca a associação de habilidades, políticas, técnicas e práticas bem definidas (Chiavenato, 2014).

Diante de um mundo mutável, instável e altamente competitivo, os colaboradores se tornaram questão vital para o sucesso das organizações. Por este motivo, os processos de desenvolvimento de pessoas tornam-se de grande relevância para as empresas (Milkovich \& Boudreau, 2000; Kanaane \& Ortigoso, 2001).

Assim as organizações investem cada vez mais em políticas de treinamento e desenvolvimento com intuito que o trabalhador possa adquirir novos conhecimentos e habilidades e, neste processo, promover o desenvolvimento de suas competências. Conforme aponta Freitas (2012), o uso desta estratégia na Gestão de Pessoas tem a finalidade de obter melhores resultados, identificar problemas e sugerir soluções dentro das organizações.

\subsection{Gestão de Pessoas}

O repasse nas informações é a engrenagem principal nos programas de desenvolvimento. Na perspectiva de Freitas (2012), é através do assunto exposto nos treinamentos e a apropriação do conhecimento por parte do treinando, que possibilitará a disseminação do aprendizado para 
os demais profissionais dentro das empresas. As organizações investem em políticas de treinamento a fim de que o indivíduo possa adquirir conhecimento e habilidades, tornando capaz de executar suas tarefas. Neste processo o treinamento colabora no desenvolvimento de competências.

Na visão de Fleury e Fleury (2004), no âmbito organizacional a competência da ótica da perspectiva individual é uma particularidade do indivíduo, que propicia alto desempenho na execução das atividades, ou mediante situações adversas.

O conceito de competência não é recente, o qual vem sendo reconceituado e revalorizado acompanhando as reestruturações econômicas e produtivas. Fleury e Fleury (2001) definem competência como sendo a qualificação para executar algo. No mundo dos negócios o conceito torna se mais abrangente e intrínseco, abordando características pessoais, como conhecimento, habilidades e atitudes e desempenho na execução das atividades (Mascarenhas, 2008).

Diante deste cenário, as pessoas juntamente com suas competências e talentos jamais foram tão valorizadas. Com as crescentes transformações no mundo empresarial, cada vez mais torna-se vital para as organizações a busca por profissionais talentosos e competentes. Dando ao trabalhador e as suas competências lugar central e destaque na diferenciação de estratégias num mercado altamente competitivo, é possível obter uma nova realidade, a relevância do capital intelectual e, em contrapartida, uma elevada cobrança por parte dos trabalhadores, os quais precisam manter-se atualizados profissionalmente, capazes de desenvolverem novas habilidades e competências, adaptabilidade, competitividade, entre outros (Kilimnik, Sant'anna, \& Luz, 2004).

\section{METODOLOGIA}

\subsection{Métodos e Objetos de Estudo}

Utilizou-se pesquisa documental, através de relatórios emitidos pelas organizações selecionadas para este estudo de caso, caracterizando a coleta de informações, e ainda uma entrevista semiestruturada, composta por vinte perguntas abertas sobre o processo de desenvolvimento organizacional.

Na perspectiva de Freitas (2012), existem diferentes técnicas de se coletar dados sobre a gestão de competências em uma organização, análise institucional, missão, visão e valores, pesquisas documentais e entrevistas. Para a realização deste estudo de caso comparativo buscou-se identificar as práticas e políticas de gestão por competências, assim como as estratégias utilizadas pelas organizações selecionadas, com o intuito de treinar e desenvolver seus colaboradores.

Com a finalidade de se realizar o estudo de caso, foram coletadas informações através de entrevistas pessoais e contato telefônico com gerentes de recursos humanos de três empresas situadas no estado de Goiás, localizadas na cidade de Catalão. Como estruturação, foram definidas vinte questões direcionadas e, após a coleta de informações, as mesmas foram trabalhadas em uma matriz SWOT.

Criada entre as décadas de 1960 e 1970 pelo norte-americano Albert Humphrey, o instrumento SWOT apresenta uma análise das Strengths (Forças), Weaknesses (Fraquezas), Opportunities (Oportunidades) e Threats (Ameaças) de um determinado assunto 
para uma análise e decisões estratégicas, (Silva, Silva, Barbosa, Henrique \& Baptista, 2011). Esta ferramenta é apresentada como um instrumento preciso para a prática de análise de informações para tomadas de decisões estratégicas.

As empresas escolhidas para o estudo de caso são as maiores da região, possuem características próprias no que tange à administração e o capital financeiro, mas apresentam uma estrutura similar referente às políticas e práticas de gestão de recursos humanos. As demais empresas desta cidade não possuem práticas voltadas para o desenvolvimento e plano de carreira de seus colaboradores. Assim sendo, torna-se necessário apresentar um breve histórico de cada uma das três empresas estudadas, seus produtos e estilos de organização.

A empresa $X$ trata-se de uma multinacional no ramo agrícola, que possui 170 anos de mercado. Seu capital é fechado e sua sede se encontra em Moline, estado de Illinois, nos Estados Unidos, onde estão localizados os integrantes de seu conselho e seus acionistas. Em Catalão sua unidade possui 17 anos de atuação, com um quadro de colaboradores atual de 600 pessoas. Os produtos fabricados nesta unidade são para utilização de colheita e pulverização.

A empresa $Y$, trata-se de uma multinacional em mineração. Sua matriz está localizada em Londres, Reino Unido. No Brasil suas ações corporativas se encontram na cidade de Belo Horizonte - MG. Possui unidade de negócio em Catalão - GO há 30 anos e suas operações concentram-se na extração de minerais, mantendo um quadro de 800 colaboradores diretos. Partes de seus produtos são consumidos no Brasil e outra parte exportada para outros países. A empresa possui um capital fechado e sua propriedade pertence a acionistas.

A empresa Z é uma montadora automobilística de 100\% capital brasileiro e fechado, de um único dono. Atualmente opera na fabricação de carros para consumo nacional e internacional. Essa empresa atua há 17 anos, em Catalão, e fabrica veículos para duas grandes marcas reconhecidas no Brasil e no mundo. Possui uma capacidade de produção atual de 250 veículos por dia e um quadro de 2.400 colaboradores. Essa empresa é responsável por $52 \%$ de arrecadação de impostos do todo o município. 


\section{ANÁLISES DOS DADOS E RESULTADOS}

Tabela 1: Matriz SWOT das três empresas estudadas.

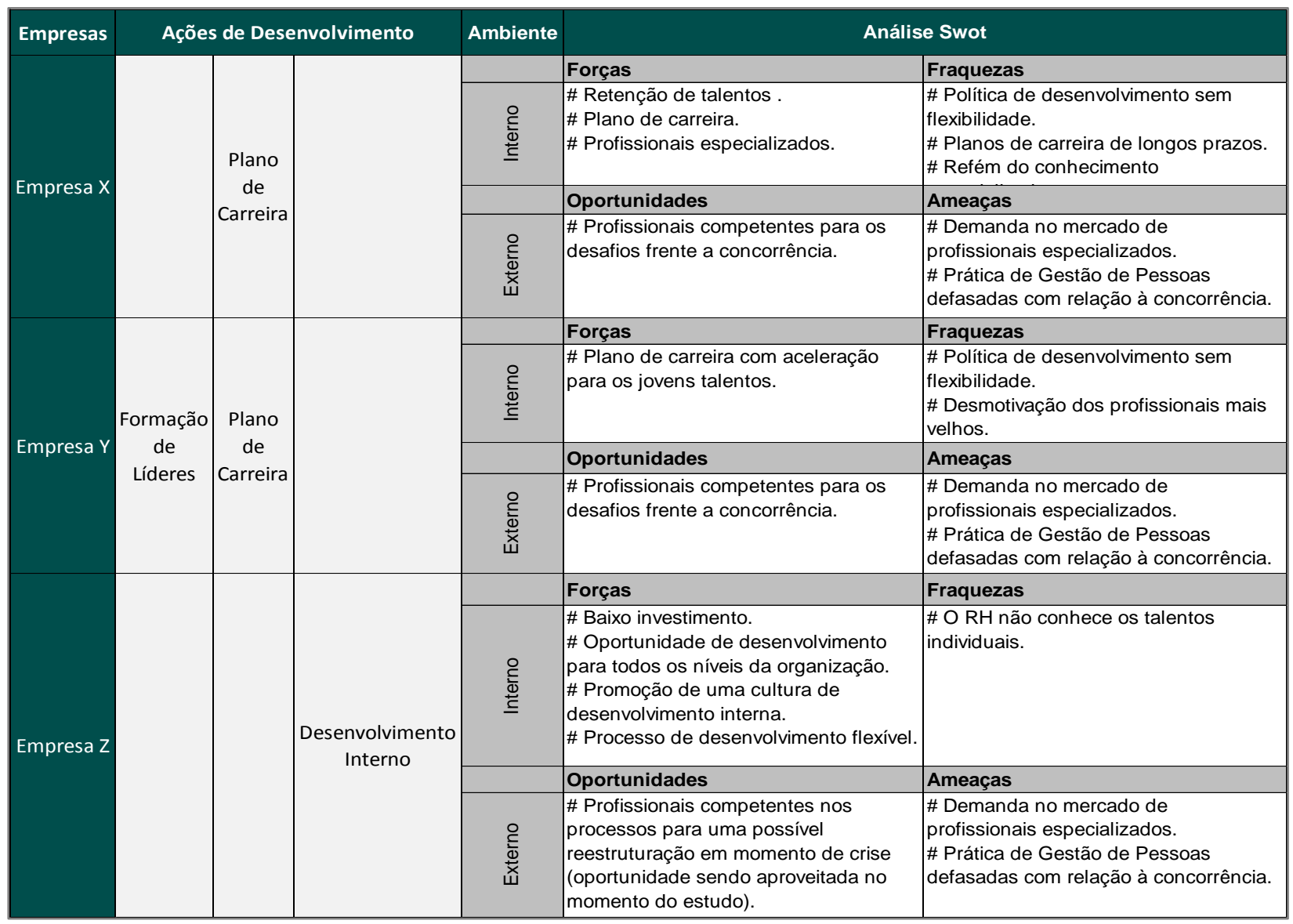

Fonte: Elaboração própria.

A empresa $X$ incentiva o treinamento e desenvolvimento de seus colaboradores de nível tático e estratégico, realizando um programa anual de treinamentos e metas individuais e coletivas. Para os colaboradores das unidades de produção não é realizado um plano de treinamento específico. As necessidades locais são atendidas de acordo com a especificidade de cada unidade.

Ambos os processos são acompanhados pela área de Treinamento e Desenvolvimento. As políticas estabelecidas para o programa de nível tático e estratégico são determinadas pela área de recursos humanos corporativos e são estabelecidas a nível mundial. O processo de treinamento e desenvolvimento é baseado em planos de carreiras internos. Seus valores são pautados em integridade e uma forte liderança, que se consolida cada vez mais em todas suas unidades de negócio. Para esta empresa, desenvolver seus colaboradores é pensar no futuro da marca e sua consolidação em todo mundo. Esta prática é exercida há vários anos e não foi identificada nenhuma busca de inovação ou transformação na gestão estratégica e desenvolvimento de pessoas. A área produtiva não tem oportunidade de treinamento e desenvolvimento como as demais, fazendo com que isso cause um descontentamento no nível operacional.

Ao passo que a empresa $\mathrm{Y}$, possui seus programas de treinamento e desenvolvimento baseados em definições corporativas para o país de atuação. A empresa trabalha com programas 
específicos de aceleramento de carreira para jovens talentosos, como programas trainees e de aprendizagem. Estes visam atender à necessidade de formação de novos profissionais dentro de seus negócios, já que possui uma forte política de retenção de talentos, o que contribui para um sólido desenvolvimento de carreira. Outro foco da empresa para seus colaboradores é o programa de preparação para aposentadoria, que é aplicado para todos os níveis da organização, com ajuda de empresa especializada que realiza uma consultoria psicológica e financeira para colaboradores com proximidade de se aposentar. Tais práticas são exercidas em todas suas unidades de atuação no Brasil e no mundo, fazendo com que grande parte de seus colaboradores, que não estão em idade de se aposentar e não tenham oportunidade de se desenvolver, alcancem novos planos de carreiras. Não foi identificado nesta empresa ações de inovação nestas políticas nos últimos cinco anos.

A empresa $Z$ possui políticas de treinamento e desenvolvimento internas, baseadas no atual cenário que a empresa se encontra, para não perder sua competitividade. Com base nisto, a área de Treinamento e Desenvolvimento buscou no mercado uma nova metodologia, ainda não executada em nenhuma automobilística do país. Este projeto de inovação nas políticas e práticas de treinamento e desenvolvimento, em uma montadora automotiva, teve uma duração de dezoito meses, com início em 2014. Em meados de 2015 a nova proposta foi apresentada para a alta direção e conselho da empresa, sendo aprovada e implantada na organização de forma sistêmica e por níveis estratégicos no início de 2016.

As competências corporativas foram definidas por meio de um estudo de desenvolvimento humano juntamente com uma consultoria de $\mathrm{RH}$. Para definição e desdobramento das competências foi realizado um trabalho interno, de acordo com cada cargo e níveis organizacionais. Essas competências foram classificadas em técnicas e comportamentais. A Figura 1 disponibiliza uma analogia com o desenvolvimento de uma árvore sendo dividida em três grupos.

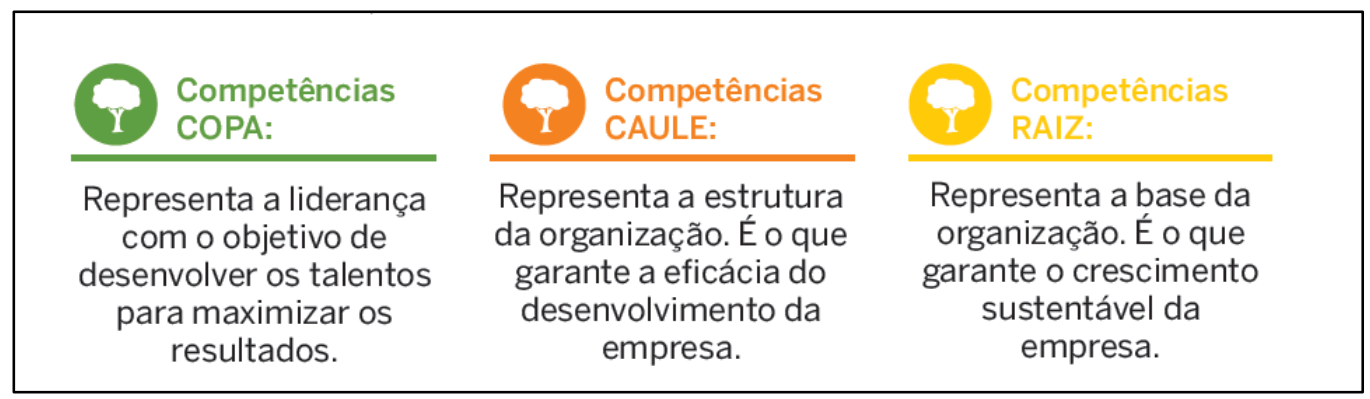

Figura 1: Classificação dos níveis de competências da organização da empresa Z.

Fonte: Elaboração própria.

A analogia à árvore conforme apresentada na Figura 1, possibilitou que todos os colaboradores entendessem as necessidades de desenvolvimento para cada nível da organização. Com base nesta definição foram classificadas cada competência em seus níveis e assim criada a árvore de competências da organização, que é utilizada nos programas de treinamento e desenvolvimento para todos os níveis e ainda estampada nas salas de reuniões, salas de treinamentos, salas de gerências e diretoria. 


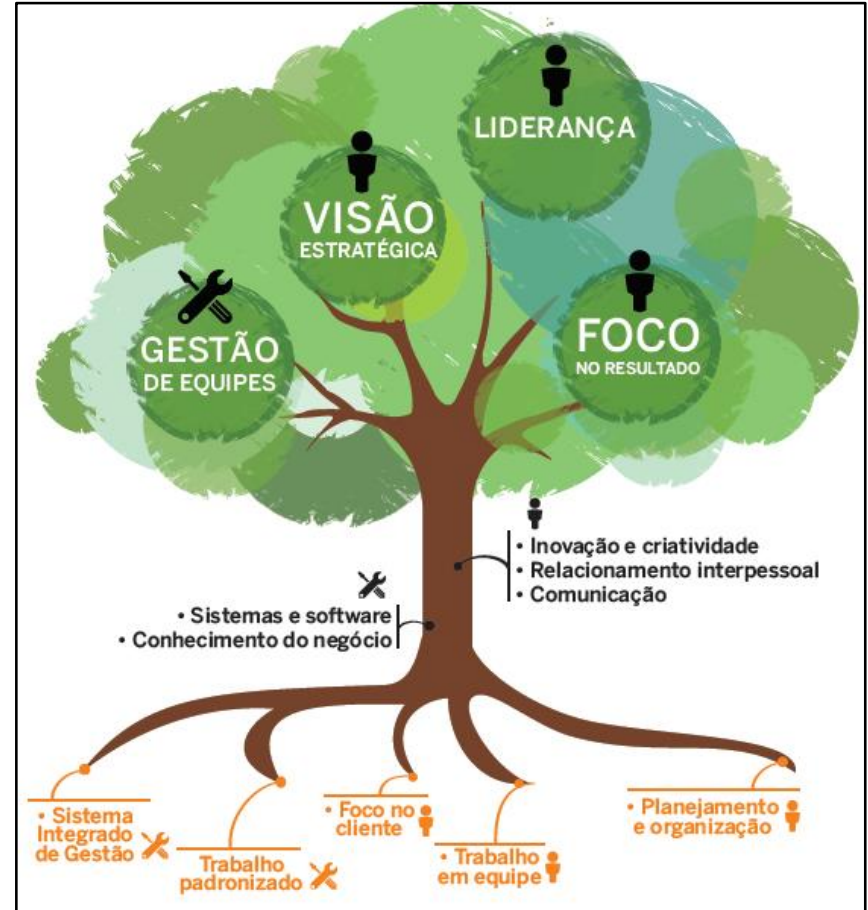

Figura 2: Árvore de competências corporativas da empresa Z.

Fonte: Elaboração própria.

Para implantação das competências corporativas foram realizadas turmas de formação para a liderança e, em seguida, para todos os níveis da organização. Esses treinamentos trataram de forma distinta a atuação da liderança e dos demais colaboradores. Para fortalecer a prática de gestão por competências, a área de treinamento e desenvolvimento identificou internamente um software, utilizado anteriormente para gestão da qualidade e, através de uma customização, passou a utilizá-lo como ferramenta de avaliação das competências.

Os gestores avaliavam seus times e, através de reuniões de feedback e consenso, identificavam as necessidades de desenvolvimento baseadas nas competências corporativas. Assim, foi traçado um plano de desenvolvimento individual chamado de PDI (Plano de Desenvolvimento Individual). Para suprir às necessidades de desenvolvimento destas competências a área de Treinamento e Desenvolvimento disponibilizou uma plataforma interna contendo 78 cursos com abrangência para todos os níveis da organização, desde uma qualificação a uma atualização. Todos os treinamentos são ministrados por instrutores internos, evitando assim um custo para a organização, além de ferramentas que dão suporte para todos os colaboradores nos diversos níveis da organização como: avaliações psicológicas, análises de perfis, mentoring, coaching, diários de bordo, etc.

Anualmente o ciclo de desenvolvimento é acompanhado pelo gestor, o qual acompanha o PDI, através de reuniões periódicas de feedback. Para concluir a fase de implantação da política de treinamento e desenvolvimento da empresa $Z$, a área de recursos humanos recebe avaliações de nível gerencial sobre o novo processo de treinamento e desenvolvimento. 


\section{CONCLUSÕES}

As três empresas citadas praticam diferentes políticas de treinamento e desenvolvimento de seus colaboradores. No entanto, todas enfatizam a importância do desenvolvimento dos seus profissionais, levando em consideração a velocidade nas mudanças de cenários vivenciados, seja no mundo político, econômico e até mesmo tecnológico. Freitas (2012, p. 07), argumenta sobre este assunto, tratando o desenvolvimento como parte estratégica dentro das organizações: "esse ambiente em que as organizações estão inseridas exigem delas uma grande capacidade de adaptação para que possam sobreviver. É a partir do desenvolvimento organizacional que procura responder a estas mudanças científicas, tecnológicas, sociais, econômicas, políticas, etc.".

Entende-se que a área de Treinamento e Desenvolvimento precisa estar em sintonia com a estratégia da empresa, a fim de desenvolver as competências dos seus colaboradores para ajudar a organização a inovar, crescer e manter se sustentável no mercado em que atua. Para isso a inovação de programas de desenvolvimento torna-se essencial para qualquer organização.

Assim sendo, pode-se entender que em todas as empresas estudadas existem oportunidades de inovação nesta área estratégica para a organização, sendo necessária iniciativa da área de Recursos Humanos/Treinamento e Desenvolvimento para promover transformações significativas neste processo, mesmo em momentos de crise. Foi possível identificar esta iniciativa na empresa $Z$ que buscou uma inovação que pode ser aplicada em outras montadoras automobilísticas e ainda em qualquer tipo de organização, levando em consideração aspectos e oportunidades nos seus talentos internos. A empresa demonstrou que, além de promover uma gestão de conhecimento, dando oportunidade para que seus colaboradores dividam seus conhecimentos e habilidades, há uma promoção de autoconhecimento e desenvolvimento, fazendo com que cada indivíduo descubra seus talentos e fortaleça suas necessidades de desenvolvimento.

\section{AGRADECIMENTOS}

Os autores agradecem às agências de fomento CNPq, CAPES e FAPEG pelo suporte financeiro que possibilitou esta pesquisa e à Universidade Federal de Goiás.

\section{REFERÊNCIAS}

Chiavenato, I. (2010). Gestão de pessoas: o novo papel dos recursos humanos nas organizações. 3 ed. - Rio de Janeiro: Elsevier.

Chiavenato, I. (2014). Gestão de pessoas: o novo papel dos recursos humanos nas organizações. 4 ed. -, Baueri-SP: Manole.

Fleury, M. T. L., \& Fleury, A. (2001). Construindo o conceito de competência. Revista de administração contemporânea, 5(SPE), 183-196.

Fleury, M. T. L., \& Fleury, A. C. C. (2004). Alinhando estratégia e competências. Revista de administração de empresas, 44(1), 44-57.

Freitas, J. C. T. D. (2012). Estratégia organizacional: Utilizando a política de treinamento e 
desenvolvimento como vantagem competitiva. IX SEG e T Simpósio de Excelência em Gestão e Tecnologia.

Kanaane, R., \& Ortigoso, S. A. F. (2000). Manual de treinamento e desenvolvimento Do Potencial Humano. Editora Atlas SA.

Kilimnik, Z. M., Sant'anna, A. D. S., \& Luz, T. R. D. (2004). Competências profissionais e modernidade organizacional: coerência ou contradição? Revista de Administração de Empresas, 44(SPE), 10-21.

Mascarenhas, A. O. (2008). Gestão estratégica de pessoas: evolução, teoria e critica. São Paulo: Cengage Learning.

Milkovich, G T. \& Boudreau, J W. (2000). Administração de recursos humanos. São Paulo: Atlas.

Silva, A. A., Silva, N. S. D., Barbosa, V. D. A., Henrique, M. R., \& Baptista, J. A. (2011). A utilização da matriz Swot como ferramenta estratégica - um estudo de caso em uma escola de idioma de São Paulo. Simpósio de Excelência em Gestão e Tecnologia, 8. 